\title{
Endoscopic submucosal dissection of a large pedunculated gastric lesion: avoiding massive bleeding to achieve en bloc resection
}

A 72-year-old woman with long-term dyspepsia underwent an outpatient upper gastrointestinal endoscopy, which showed a large pedunculated polypoid lesion of $30 \mathrm{~mm}$ on the lesser curvature of the gastric body ( $\triangleright$ Fig. 1 a). As endoscopic biopsies showed tubulovillous adenoma with low grade dysplasia, the patient was referred to the hospital for endoscopic resection. Pre-procedural reassessment using virtual chromoendoscopy (narrow-band imaging [NBI]) revealed areas with an irregular glandular and vascular pattern in the pedicle and surrounding mucosa, with biopsies confirming low grade dysplasia in both sites. En bloc resection through endoscopic submucosal dissection (ESD) using an IT Knife 2 was therefore planned ( Video 1) as conventional polypectomy techniques would have been associated with a high probability of piecemeal/ incomplete resection. During ESD, a large ( $5 \mathrm{~mm}$ ) dominant vessel was identified at the center of the implantation point of the lesion in an area corresponding to the pedicle, which would need to be dissected to achieve a successful resection ( $>$ Fig.1 b). Initial selective dissection of the surrounding submucosa was performed, with subsequent vessel ligation using three hemostatic clips, which thereby allowed for complete en bloc excision, avoiding the potential for associated bleeding ( $>$ Fig.2). No post-ESD complications were observed.

Histology of the resected specimen confirmed an $\mathrm{R} 0$ resection of a 50-mm adenomatous lesion with extensive dysplasia (both low and high grade) and focal areas of intramucosal carcinoma ( $>$ Fig. 3 ). The patient has subsequently continued on endoscopic follow-up, with no evidence of recurrence.

Gastric cancer is the fifth most common cancer worldwide and the third leading cause of death from oncologic disease

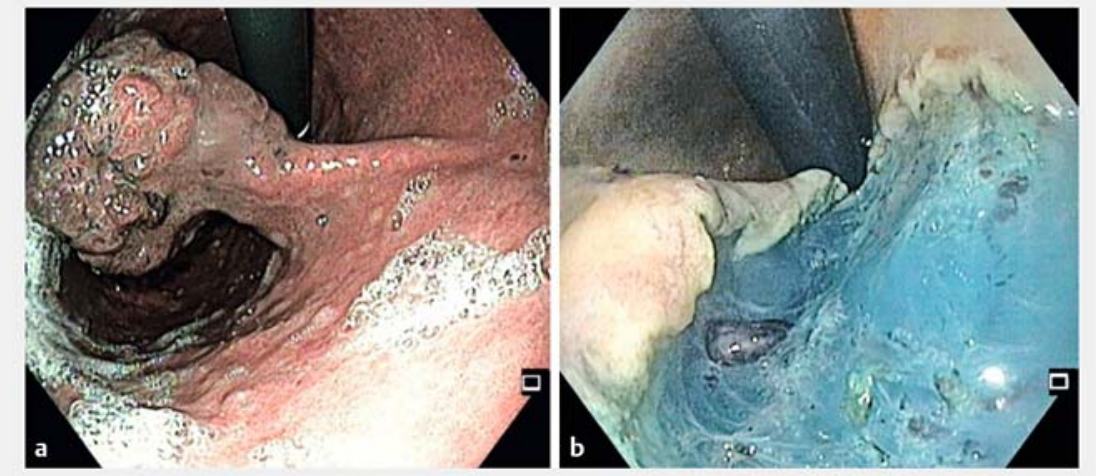

- Fig. 1 Endoscopic images showing: a a large pedunculated gastric lesion located on the lesser curvature; $\mathbf{b}$ the large vessel in the submucosa that was found incidentally during endoscopic submucosal dissection.
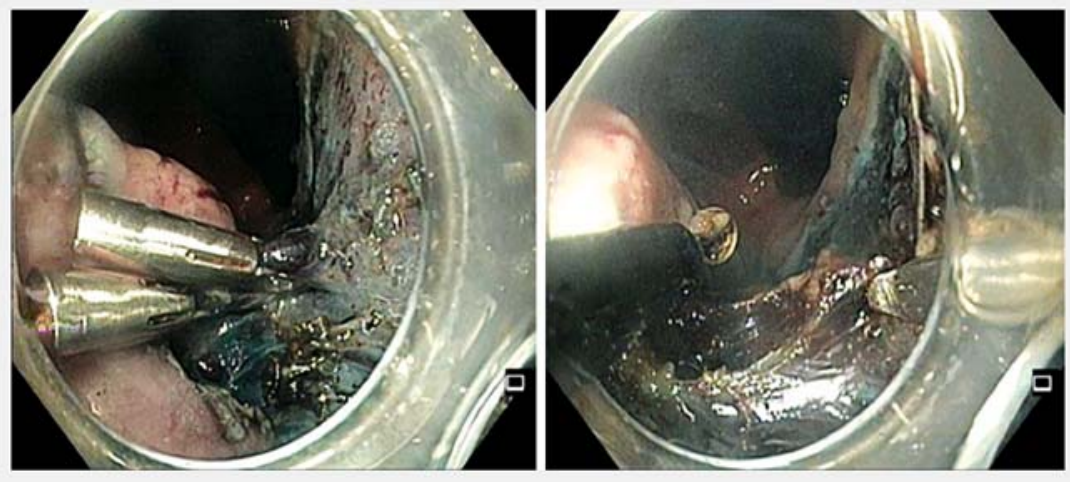

Fig. 2 Following selective dissection of the surrounding submucosa, the vessel has been ligated with endoscopic clips, allowing endoscopic submucosal dissection to be completed without significant bleeding.

[1]. Gastric pedunculated polyps are often resected through hot snare polypectomy. Nevertheless, alternative techniques should be considered if a risk of incomplete resection owing to dysplasia in the implantation base is evident [2,3]. The present case and accompanying video demonstrate an effective endoscopic approach to the finding of an unexpected large vessel and highlight that
ESD may be a good option to decrease the risk of massive bleeding in gastric lesions with a large pedicle.

Endoscopy_UCTN_Code_TTT_1AO_2AG

Competing interests

None 


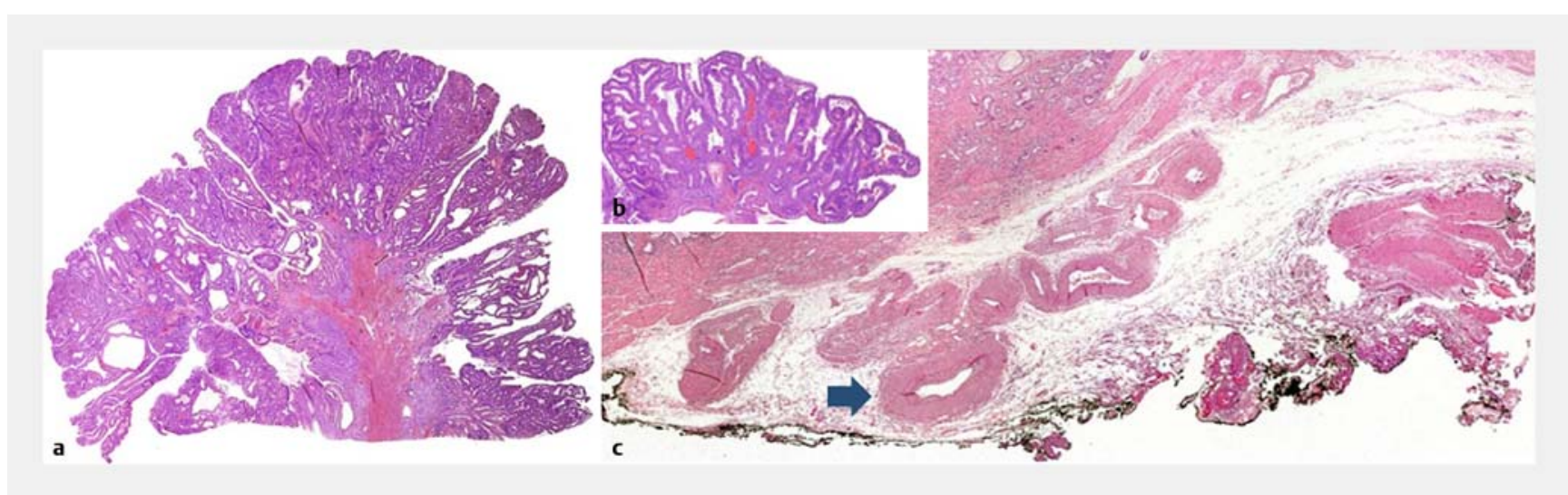

- Fig. 3 Histology of the lesion, which was confirmed as an R0 resection, showing: a a tubular adenoma with low grade and high grade dysplasia in the head of the lesion; $\mathbf{b}$ one focal area of intramucosal adenocarcinoma; $\mathbf{c}$ the large dominant vessel (blue arrow) in the pedicle of the polyp.

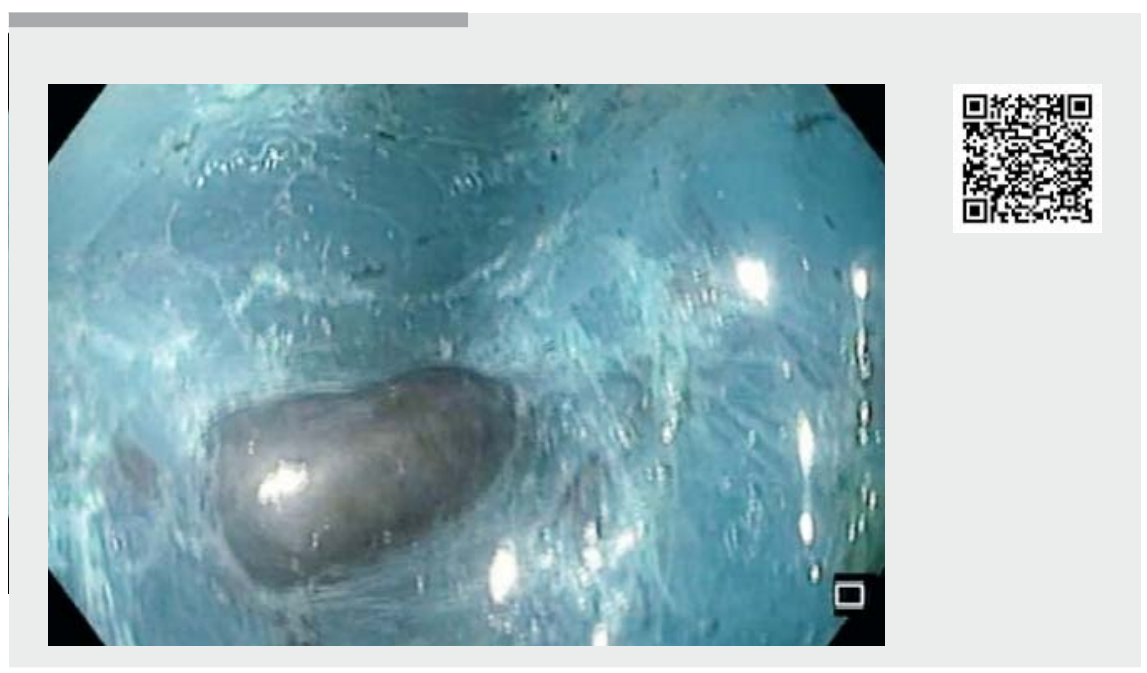

Video 1 Endoscopic submucosal dissection of a large gastric pedunculated lesion.

The authors

Gonçalo Nunes ${ }^{1}$, Diogo Libânio ${ }^{2,3}$, Rui Castro², Inês Marques-de-Sá ${ }^{2}$, Davide Gigliano ${ }^{4}$, Mário Dinis-Ribeiro $^{2,3}$

1 Gastroenterology department, Hospital Garcia de Orta, Almada, Portugal

2 Gastroenterology department, Instituto Português de Oncologia Francisco Gentil, Porto, Portugal

3 Center for Research in Health Technologies and Information Systems (CINTESIS), Faculty of Medicine, University of Porto, Porto, Portugal

4 Pathology department, Instituto Português de Oncologia Francisco Gentil, Porto, Portugal

[2] Castro R, Pimentel-Nunes P, Dinis-Ribeiro M. Evaluation and management of gastric epithelial polyps. Best Pract Res Clin Gastroenterol 2017; 31: $381-387$

[3] Pimentel-Nunes P, Dinis-Ribeiro M, Ponchon $T$ et al. Endoscopic submucosal dissection: European Society of Gastrointestinal Endoscopy (ESGE) Guideline. Endoscopy 2015; 47 : $829-854$

\section{Bibliography}

DOI https://doi.org/10.1055/a-0965-6431

Published online: 24.7.2019

Endoscopy 2019; 51: E404-E405

(c) Georg Thieme Verlag KG

Stuttgart · New York

ISSN 0013-726X

\section{ENDOSCOPY E-VIDEOS \\ https://eref.thieme.de/e-videos}

Corresponding author

\section{Gonçalo Nunes, MD}

Gastroenterology department, Hospital Garcia de Orta, Av. Torrado da Silva, 2805-267 Almada, Portugal goncalo.n@hotmail.com

\section{References}

[1] Ferlay J, Soerjomataram I, Dikshit R et al. Cancer incidence and mortality worldwide: sources, methods and major patterns in GLOBOCAN 2012. Int J Cancer 2015; 136 : E359-E386 